NASA Technical Memorandum 100113

AIAA-87-2120

\title{
Preliminary Performance Characterizations of an Engineering Model Multipropellant Resistojet for Space Station Application
}

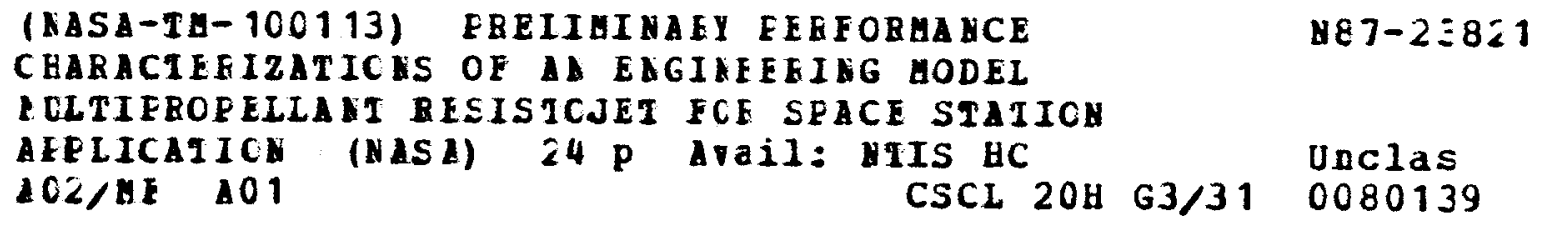

W. Earl Morren

Lewis Research Center

Cleveland, Ohio

Stuart S. Hay

Purdue University

West Lafayette, Indiana

Thomas W. Haag and James S. Sovey

Lewis Research Center

Cleveland, Ohio

Prepared for the

23rd Joint Propulsion Conference

cosponsored by the AIAA, SAE, ASME, and ASEE

San Diego California, June 29-July 2, 1987 
PRELIMINARY PERFORMANCE CHARACTERIZATIONS OF AN ENGINEERING MODEL

\title{
MULTIPROPEI.LANT RESISTOJEI FOR SPACE STATION APPLICATION
}

\author{
W. Earl Morren \\ National Aeronautics and Space Administration \\ Lewis Research Center \\ Cleveland, Ohio 44135 \\ Stuart S. Hay \\ Purdue University \\ West Lafayette, Indiana 47907 \\ and \\ Thomas W. Haag and James S. Sovey \\ National Aeronautics and Space Administration \\ Lewis Research Center \\ Cleveland, Ohio 44135
}

\section{SUMMARY}

This paper presents the results of a program to describe the operational characteristics of an engineering model multipropellant resistojet for application as an auxiliary propulsion system for space station. Performance was measured on hydrogen, helium, methane, water (steam), nitrogen, air, argon, and carbon dioxide. Thrust levels ranged from 109 to $355 \mathrm{mN}$, power levels ranged from 167 to $506 \mathrm{~W}$, and specific impulse values ranged from 93 to $385 \mathrm{sec}$, depending upon the propellant, chamber pressure, and heater current level selected. Detailed thermal maps of the heater and heat exchanger were also obtained for operation with carbon dioxide.

\section{INTRODUCTION}

This paper presents the results of a test program designed to describe the operating characteristics of an engineering model multipropellant resistojet. The multipropellant resistojet has been baselined as the low-thrust option for the space station propulsion system. The resistojet can provide low levels of thrust for drag make-up while disposing of a variety of fluids expected to be present in excess quantities on board space station. The use of such fluids as propellants will result in significant reductions in Space Transportation System costs which would be associated with launching of the necessary propellants as well as the removal of waste fluids from space station. Recent studies have explored these and other potential benefits of a propulsion system incorporating low-thrust resistojets (refs. 1 and 2 ).

The NASA Lewis Research Center is actively involved in propulsion component technology in support of the space station Advanced Development Program (refs. 3 and 4 ). A substantial part of these efforts has focused on material evaluation (ref. 5), fabrication methods, performance, plume evaluations (ref. 6), power processing (ref. 7), and life assessments of resistojet technology for space station application (ref. 8). Preliminary system requirements and propulsion module definition have begun (refs. 9 and 10). The technology 
goals emphasize thruster life, reliability, and multipropellant capability rather than optimum performance. The design life goal is a minimum of

$10000 \mathrm{hr}$ for thrusters operating on hydrogen, helium, methane, water (steam), nitrogen, air, argon, and carbon dioxide at specific impulse and thrust levels of 100 to $500 / \mathrm{sec}$ and 130 to $450 \mathrm{mN}$, respectively.

The main objective of this program was to evaiuate the operating characteristics of an engineering model multipropellant resistojet which was designed and fabricated by the Rocketdyne Division of Rockwe 11 International and Technion Incorporated as part of the Space Station Advanced Development Program. The engineering model thruster incorporates design features which enable it to operate on a wide variety of fluids for extended periods of time. This thruster was characterized on the above mentioned fluids. Performance data were obtained for each propellant (except steam) at two thrust levels for each of two input electric power levels. Data were obtained for steam operation at a variety of power levels for each of two conditions: steam supplied to the thruster from a water vaporizer and liquid fed directly to the thruster.

Detailed information about the temperature distribution within the heater and heat exchanger was also obtained for operation with carbon dioxide. The thermal transient behavior of the engineering model was investigated for operation with carbon dioxide and argon. The information gained from these tests served as input to a design iteration intended to enhance the operational and reliability characteristics as well as simplify the fabrication of the resistojet.

\section{APPARATUS AND PROCEDURE}

\section{Engineering Model Thruster Description}

The design details of the engineering model thruster have been described in reference 11 , but will be reviewed here for convenience.

The material used for construction of the engineering model thruster was grain-stabilized platinum because it exhibits long-term, high-temperature com patibility with a wide variety of oxydizing and reducing fluids. The component parts of the heat exchanger were fabricated and assembled by Johnson-Matthey, and contained a small quantity (less than 1 percent) of zirconium oxide dispersant as a grain stabilizer to minimize grain growth which occurs when materials are held at high temperatures for extended periods of time (ref. 8$)$. Excessive grain growth leads to distortion and weakening of components, which is of special concern for the pressure vessel/heat exchanger of a resistojet.

The engineering model multipropellant resistojet, shown in figure 1 , consists of a central cylindrical heat exchanger inside a colled sheathed heater. This assembly is surrounded by several layers of radiation shields and encased in a cylindrical shroud which serves as a mounting and support structure for the heat exchanger/heater/radiation shield assembly. The heat exchanger incorporates thick pressure vessel walls designed to resist stress rupture for a minimum of $10000 \mathrm{hr}$ at temperatures and internal pressures of interest. Table I summarizes the design features of the engineering model thruster.

The heat exchanger shell is cylindrical with a series of semicircular grooves machined into the downstream half of the outer surface which retain the coiled sheathed heater, insuring proper location of the heater and providing a large surface area for conduction from the heater to the heat exchanger. The 
pressure vessel contains a hollow core cylinder, sealed at the downstream end, designed to force the incoming propellant through a series of 36 axial channeis between the outer core surface and the inner heat exchanger surface. The core is present only in the upstream half of the heat exchanger due to difficulties encountered during assembly of the unit tested, which was the first engineering model produced. The design of the heat exchanger/core interface has been successfully changed to eliminate such difficulties in subsequent iterations. The upstream end of the pressure vessel contains a flange which incorporates the propellant inlet tube and the downstream end of the pressure vessel is terminated with a nozzle. The three pressure vessel components are joined by largesurface area diffusion bonds which serve as stress-bearing joints. The diffusion bonds are backed by electron beam welds to insure a positive gas sea 1 . The diffusion bonds are used in relatively high-temperature, high-stress locations, since this joining technique does not destroy the grain stabilization, as does electron beam welding. The heater employed was manufactured by Englehard Industries, and consists of a rugged $1.6 \mathrm{~mm}$ diameter platinum-rhodium center conductor surrounded by a layer of magnesium oxide insulator, all of which is contained within a grain-stabilized platinum sheath. This assembly is processed by swaging to compact the magnesia insulator between the sheath and center conductor, insuring proper centering of the center conductor within the sheath and eliminating any possibility of heater failure due to shorting. The heater is wound in. a double helix configuration which allows both power leads to be located in the c0ol upstream end of the thruster, enhancing the reliability of the heater termination assembly.

The radiation shield pack which surrounds the heater coil consists of ten layers of foil separated by small-diameter wire. The three layers of shielding closest to the heat exchanger are made of platinum, since the temperatures in this region during operation are relatively high, while the remaining seven layers are made of nickel. The support shroud is made of inconel, and serves to protect the heat exchanger and shield pack while providing for mounting of the thruster. This shroud contains a series of small holes in the nozzle end which provide for evacuation of the radiation shield pack. In addition, this insures that any propellant leaking from the pressure vessel as a result of failure would vent propulsively, satisfying a fail-operational design criterion.

\section{Performance Characterization Apparatus}

The performance of the engineering model multipropellant resistojet was characterized using a thrust measurement system developed and fabricated at NASA Lewis. This system is of the calibrated displacement type, and is shown schematically in figure 2. The design details of this system are described in reference 12 .

The operating parameters monitored during characterization on the seven gaseous propellants included propellant inlet pressure and mass flow rate, heater voltage and current, and thrust. Propellant inlet pressure was measured using an electronic pressure transducer with a range of 0 to $3.4 \mathrm{MPa}$ absolute. The mass flow rate was measured using commercially-available instruments which are sensitive to the heat capacity of the flowing fluid. These mass flow meters were calibrated for operation on all propellants tested except water, which was incompatible with the meter in both liquid and vapor states. The 
uncertainty in measured mass flow rates was estimated to be less than 1 percent.

The engineering model resistojet was characterized on water supplied to the thruster in both liquid and vapor states. Providing the thruster with vaporized water required the use of a steam generator upstream of the thruster. The steam generator employed was similar to a design described in reference 13. Water was supplied to the water vaporizer from a pressurized reservoir and exhausted from the vaporizer through a heated feed line leading to the thruster. The mass flow rate of the water was obtained using a graduated sight tube located upstream of the vaporizer. Supplying the steam to the thrust stand required modification of the flexures which produced some undesirable operating characteristics of the thrust stand. Consequently the uncertainty in the thrust measurements obtained for vapor-fed steam operation are larger than for the other fluids tested, but are still estimated to be less than 6 percent. Operation of the engineering model in a liquid water-fed mode eliminated the need for modification of the thrust stand flexures. However, it was necessary to install a flow restriction in the propellant feed tube directly upstream of the thruster inlet. This consisted of a $0.38 \mathrm{~mm}$ id capillary tube with the outlet located at the propellant inlet/heat exchanger interface.

No corrections to the thrust measurements were made to account for vacuum facility pressure, which was typically between 200 and $500 \mu \mathrm{m}$, or effects associated with propellant recirculation. These corrections are not straightforward for the engineering model thruster due to uncertainties in the nozzle exit plane area upon which such corrections should be based. Errors in corrected thrust values for operation at relatively high test cell pressures (greater than $10 \mu \mathrm{m}$ ) are most likely related to increased thermal losses through radiation shields (ref. 14). These errors were shown to reduce the measured specific impulse by as much as 7 percent relative to values which could be obtained in a hard vacuum. Additional errors in the values reported herein are most likely due to nozzle shock (ref. 15), and additional tests in a test chamber capable of maintaining lower pressures will be required for quantification.

\section{Performance Tests}

Performance data was obtained for each of two heater current levels at each of two propellant inlet pressure levels for seven of the eight fluids of interest: hydrogen, helium, methane, nitrogen, air, argon, and carbon dioxide. Performance data for water (the eighth fluid) was restricted to only one pressure level each for vapor-and liquid-fed operation at each of four power levels. Table II shows the test matrix for performance characterizations performed.

\section{Thermal Mapping}

The outer surface of the engineering model thruster was observed using an infrared thermal imaging system so that any unexpected temperature distributions could be identified. These tests were conducted with the thruster operating on carbon dioxide propellant at conditions similar to those present during some of the performance tests. Although the thermal imaging system was 
not calibrated to yield actual temperature readings, regions of high tempera ture could be identified readily on a relative basis. Several thermocouples were also installed on the thruster shroud so that temperatures at potential hot spots shown by the IR thermographer could be quantified.

The temperature distribution within the thruster under steady and transient conditions was investigated in an effort to identify the relationship between the heater resistance and the maximum temperature within the thruster. This information was necessary so that the safe operating limits of this design could be defined without risking fallure of any of the thruster components due to overheating. Holes were cut in the containment shroud at three locations: near the nozzle, at the center of the heat exchanger, and near the propellant inlet. Thermocouples were installed at locations on the heater, heat exchanger, nozzle, propellant inlet tube, and heater terminations.

\section{Test Facility}

The performance tests were conducted in a vacuum chamber measuring $1.1 \mathrm{~m}$ in diameter by $4.6 \mathrm{~m}$ long, and equipped with a mechanical blower backed by a rotary piston vacuum pump. This facility was capable of maintaining tank pres. sure below $67 \mathrm{~Pa}(0.5$ torr) during operation of the resistojet on all fluids tested. Operation on steam necessitated addition of gas ballast to the mechanical pump which caused a slight reduction in pumping capacity.

\section{RESULTS AND DISCUSSION}

\section{Performance Characterizations}

The engineering model resistojet was designed to operate on a wide variety of fluids expected to be available in excess quantities on board space station. Therefore it was desired to evaluate the performance characteristics of this design on as many of these fluids as was practical. Seven of the fluids, hydrogen, helium, methane, nitrogen, air, argon, and carbon dioxide, are gaseous at feed pressures of interest for operation of the engineering model thruster. However, the final fluid, water, requires significant inputs of energy to vaporize at these pressures and so was treated separately from the other propellants.

The power levels chosen for the performance characterization tests were based on the established temperature limits of the grain-stabilized platinum thruster material. Prior to assembly of the thruster the heater was calibrated for temperature as a function of resistance. From this calibration it was determined that the maximum al lowable heater temperature of $1400{ }^{\circ} \mathrm{C}$ would be achieved at a resistance of $1.0 \Omega$ with the heater at uniform temperature. Upon initial testing of the engineering model thruster it was learned that an equilibrium heater resistance of $1.0 \Omega$ was achieved at a current level of $23.0 \mathrm{~A}$ with no propellant flowing through the heat exchanger. Since significant temperature gradients were expected to be present over the length of the heater during operation with flowing propellant, it was unlikely that the heater resistance would be a valid indicator of the maximum heater temperature. Therefore it was decided not to exceed a current level of $23.0 \mathrm{~A}$ at equilibrium during operation, regardless of the fluid being used for propellant. Although this was known to be a conservative operating limit, the lack of data relating 
the heater resistance to actual maximum temperature as well as the fact that only one engineering model thruster existed required such a precaution.

The maximum current level of 23.0 A established the maximum power level for each fluid. It was also desired to obtain data at a second, lower power level. A heater current level of 18.5 A generally yielded a power level approximately half that obtained at $23.0 \mathrm{~A}$, so this current level was chosen as the second of the two operating power set points.

The remaining operating parameter, thrust, was chosen based on the assumption that the engineering model thruster would be operated in a pressureregulated mode in flight. Two propellant inlet pressures were chosen which would yield thrust levels at the expected limits of operation. These pressures were 0.14 and $0.27 \mathrm{MPa}$. The choice of current-regulated operation at fixed inlet pressure caused the power dissipated by the heater to vary widely from one propellant to the next due to the range of heat capacities of the various fluids. Figure 3 shows the relationships between heater resistance and heater power for the seven gaseous propellants at an input propellant pressure of $0.21 \mathrm{MPa}$. As expected, the heater temperature at constant current was lower for gases with higher specific heats. Also shown is a line of constant voltage for the various gases. The value for which the constant voltage line is shown was chosen because extrapolation of the hydrogen data points to a power level of $500 \mathrm{~W}$ yielded a heater resistance of $0.6 \Omega$, requiring a voltage of $17.3 \mathrm{~V}$. Thus for a multipropellant system required to operate at constant voltage with a maximum power level of $500 \mathrm{~W}$, one could use figure 3 to determine the current and the heater temperature which would result from operation with a given propellant. The voltage and current for constant-power operation on the fluids tested could also be obtained.

Figure 4 shows the range of specific impulse obtained at various power levels for operation at a constant propellant inlet pressure of $0.14 \mathrm{MPa}$. The nominal thrust levels measured are shown, as are the corresponding cold gas specific impulse values. As expected, the specific impulse decreases with increasing molecular weight. Although the absolute value of specific impulse for the lighter fluids (hydrogen, helium) is rather low, it should be noted that the power levels tested were highly conservative. Operation on all of the tested fluids at a fixed power level of $500 \mathrm{~W}$ would have shown greater specific impulse values for the fluids with higher specific heats. Subsequent tests at power levels as high as $740 \mathrm{~W}$ using carbon dioxide propellant produced maximum thruster temperatures of about $1200^{\circ} \mathrm{C}$. Figure 5 is similar to figure 4 except the propellant inlet pressure is higher $(0.27 \mathrm{MPa})$. The trends exhibited are the same although, as expected, the specific impulse values are lower than for the lower-thrust operation. Performance data obtained for operation on the seven gaseous propellants tested are given in the appendix, tables A-1 through A-7.

\section{Steam Operation}

The use of water as a propellant for the engineering model resistojet poses problems not encountered with the other propellants tested. Water is most convenientiy stored as a liquid and requires significant input of energy to vaporize. This raises questions about the best manner in which to vaporize the liquid so that it may be superheated and expelled through the nozzle. One 
could envision two systems: the first of these employs a separate water vaporizer upstream of the thruster with the thruster serving only to superheat the steam (ref. 13); the second would combine the vaporizing and superheating functions into a single unit (ref. 16). Since the engineering model thruster was originally envisioned to operate on steam in combination with a separate steam generator, it was never optimized to perform as a water vaporizer. However, it was decided during the performance testing program to make minor modifications to the engineering model to facilitate operation as a liquid water-fed thruster.

The decoupled system (i.e., the system employing the separate boiler) appeared to operate in a manner very similar to the seven gaseous propellant systems discussed earlier, since the fluid entering the heat exchanger was already a vapor and required only superheating. Since the range of operating capabilities of the boiler was limited, only one propellant inlet pressure setting was tested $(0.21 \mathrm{MPa})$, although four total power levels ranging from 780 to $1160 \mathrm{~W}$ were examined. The decoupled system demonstrated a maximum specific impulse of $184 / \mathrm{sec}$ at a thrust level of $230 \mathrm{mN}$ while consuming $466 \mathrm{~W}$ in the water vaporizer and $692 \mathrm{~W}$ in the thruster. The heater temperature near the nozzle under these conditions was measured to be about $1140^{\circ} \mathrm{C}$.

The coupled system required the thruster to act as a boiler and superheater. Therefore the thruster operated at high temperatures to perform the superheating, causing a large temperature difference between the incoming liquid and the heat exchanger walls. This was an undesirable condition according to traditional boller design practice, which calls for a thin layer of liquid in contact with the heat exchanger wall. Such a condition would require a liquid-to-wall temperature difference on the order of $50{ }^{\circ} \mathrm{C}$. However, the room-temperature liquid fed directly into the thruster encountered wall temperatures as high as $700{ }^{\circ} \mathrm{C}$, which would cause the incoming liquid stream to flash to a mixture of superheated vapor and liquid droplets. The range of stable operation was narrower for the coupled system than for the decoupled system, so the power levels and thrust levels tested were highly interdependent. Four power levels ranging from 200 to $500 \mathrm{~W}$, each at a unique thrust level, were tested. Figure 6 shows the relation between specific impulse and the ratio of input electric power to propellant mass flow rate for all of the operating conditions tested using water propellant. The coupled system demonstrated a maximum specific impulse of $159 / \mathrm{sec}$ at a thrust level of $84 \mathrm{mN}$ while consuming $289 \mathrm{~W}$. The heater temperature near the nozzle under these conditions was approximately $600{ }^{\circ} \mathrm{C}$. The large variations in the data obtained from the coupled system as compared to the data from the decoupled system are due to the relatively low flow rates experienced with the coupled system. These were typically only one-third the flow rates of the decoupled system, so the resulting uncertainty in mass flow rate was much larger for the coupled system. Figure 6 shows that no significant performance advantages exist for either water-feeding scheme over its alternative.

Performance data obtained for vapor- and liquid-fed operation on water are given in tables $A-8$ and $A-9$, respectively. It should be noted that the data presented for steam operation does not represent an exhaustive test series, as would be required to thoroughly define the performance envelope of the engineering model resistojet using either liquid or vaporous water propellant. A program to define the design characteristics of a fight-type water vaporizer has begun at NASA Lewis, and will examine both decoupled and coupled systems. 
To investigate the thermal characteristics of the engineering model thruster an infrared thermal imaging system was used to observe the temperature distribution on the outside of the containment shroud while the thruster was operated on carbon dioxide under conditions similar to those investigated during the performance testing. Figure 7 shows a photograph of the image produce by the IR thermographer. The outer shell of the thruster is hotter near the inlet and near the nozzle than in the center. This was as expected, since the heat exchanger is supported by the shroud only at these two locations, and each is a conduction path from the heater to the shroud. However, the azimuthal temperature distribution at the nozzle end of the shroud showed significant variation, with maximum temperature differences of approximately $150^{\circ} \mathrm{C}$ under some operating conditions. This can be seen by the lightly shaded area near the nozzle end of the thruster in figure 7. Thermocouple measurements on the outer surface of the thruster showed the temperature distribution to be symmetrical about a line through the center of the hot spot. This high temperature region was due to a minute gap between the nozzle and the shroud over approximately two-thirds of the circumference. The portion of this interface which showed close coupling corresponded to the observed hot zone. Thus a slight misalignment of the nozzle and shroud during assembly was the cause of the nonuniform temperature distribution. While the IR thermographer was not calibrated to obtain temperature readings during these tests, thermocouple readings were taken which enabled estimates of the various temperature regions shown in figure 7 to be made.

Following the thermal imaging tests a hole was cut through the containment shroud of the engineering model thruster to install thermocouples so that a detailed thermal map of the heater/heat exchanger assembly could be obtained. Figure 8 shows a schematic diagram of the engineering model thruster as we 11 as thermocouple readings obtained at several locations on the heater, heat exchanger, power leads, and nozzle. The propellant used during these tests was carbon dioxide, and the operating conditions were approximately $335 \mathrm{mN}$ at $120 / \mathrm{sec}$ specific impulse. It is interesting to note that the temperature of the heater coil varied less than $300{ }^{\circ} \mathrm{C}$ over its entire length, and that the return loop near the nozzle operated below the maximum heater temperature even though the only modes for dissipation of energy from this region were radiation to the nozzle and conduction through itself back to the heat exchanger. This result was not expected, but is fortuitous in that the return loop is not a limiter of the operating condition. The significance of the relatively small temperature gradient along the heater coll is that the uncertainty in the temperature at any point along the heater as obtained from the temperatureresistance calibration performed prior to assembly of the thruster should be sma 11. This calibration could not be used as a diagnostic tool in the presence of large temperature gradients since the resistance measured would indicate the average heater temperature without yielding information about the range of temperatures present in the heater. While a $300{ }^{\circ} \mathrm{C}$ temperature difference may seem large, it should be noted that the heater temperature near the propellant inlet (thermocouple number 16 in fig. 8) is significantly lower than the temperature only a few turns downstream of the inlet due to conductive losses through the heater to the power leads, shroud, and cool gas inlet tube. Therefore the actual range of temperatures experienced by over 90 percent of the heater coil is much less than $300^{\circ} \mathrm{C}$ under the operating conditions examined. 
The unusually large thermal capacitance of the engineering model resistojet leads to some interesting thermal transient responses. Figures 9 and 10 show the maximum heater temperature and propellant inlet pressure, respectively, measured for transient response tests performed using carbon dioxide and argon propellants. For these tests, the thruster was heated from room tem. perature for 5 min at a constant heater current level which would result in an equilibrium power consumption of $500 \mathrm{~W}$ for each fluid. Following the 5 -min preheat, the propellant flow was initiated with the propellant inlet pressure regulated at $0.28 \mathrm{MPa}$. Once thermal equilibrium was achieved, the flow and power were shut off so the cooling rate could be observed. Typical times required to reach equilibrium at $500 \mathrm{~W}$ from cold start-up were on the order of $90 \mathrm{~min}$, although the time necessary to reach 63 and 90 of equilibrium temperatures were approximately 15 and $40 \mathrm{~min}$, respectively. Shut-down transient response showed similar time constants, with cool-down to $200{ }^{\circ} \mathrm{C}$ or less requiring more than 90 min without flow through the heat exchanger. Although the thermal time constants are long compared to other resistojet thrusters, steady state thrust levels were established almost immediately with the pressure-regulated feed system. of course, mass flow rates through such a system continued to vary in an exponentially-decaying manner until equilibrium exhaust temperature was established.

\section{Engineering Model Design Update}

The engineering model resistojet used for the tests described in this paper was the first such unit of its kind. To date, three additional units have been built. All of these thrusters are of the same general design, differing only in minor details. A fifth engineering model resistojet has been ordered based on an updated design which incorporates improvements conceived as a result of these characterization tests. Among the most significant improvements relative to the design detailed in reference 11 are associated with assembly procedures, a redesigned radiation shield pack, a modified electron beam weld procedure, and minor material specifications. This fifth iteration represents the culmination of all efforts expended toward development of the engineering model multipropellant resistojet and will carry forward as the starting point for prototype development. More detailed performance mapping, life testing, and documentation of radiated emissions will continue.

\section{CONCLUDING REMARKS}

An engineering model resistojet designed for long-term operation on a variety of propellants was characterized on eight fluids which are candidates for use as propellants on board space station. These fluids were hydrogen, helium, methane, water (steam), air, nitrogen, argon, and carbon dioxide. The engineering model thruster demonstrated acceptable performance on all fluids tested, although measured specific impulse values were relatively low. This was due to choices for operating power levels which were overly conservative. Operation using water propellant supplied to the thruster in both liquid and vapor states was stable and repeatable. A detailed thermal mapping of the thruster was obtained so that the maximum safe operating limits could be more clearly defined and thermal transient response could be evaluated. These tests revealed that the temperature distribution along the length of the heater was 
more nearly constant than initially believed. The time required to bring the engineering model to thermal equilibrium from a cold start was about 90 min and temperatures of 60 to 90 percent of the equilibrium values were achieved in 15 to 40 min, respectively. Maximum pressure levels were achieved quickly and maintained using a pressure-regulated propellant feed system.

The engineering model resistojet has proven to be a highly flexible design, capable of operating over a wide range of power and thrust levels on a variety of fluids, one of which required significant energy input to vaporize before the fluid temperature could be substantialiy increased.

\section{ACKNOWLEDGMENTS}

The authors wish to acknowledge the efforts of Gordon L. Cann, T. Kent Pugmire, and Frank $X$. Mckevitt, all of Technion Incorporated, and Bruce $J$. Heckert of Rocketdyne to supply the engineering model multipropellant resistojet for use in the space station propulsion system Advanced Development Program.

\section{REFERENCES}

1. Donovan, R.M., Sovey, J.S., and Hannum, N.B., "Space Station Propulsion Analysis Study," AIAA Paper 84-1326, June 1984. (NASA TM-83715).

2. Garrison, P.W. and Klemetson, R.W., "Space Station Propulsion System Trade Study," AIAA Paper 83-1220, June 1983.

3. Jones, R.E., "Space Station Propulsion: The Advanced Development Program at Lewis," AlAA Paper 85-1154, July 1985. (NASA TM-86999).

4. Jones, R.E., "Highand Low-Thrust Propulsion Systems for the Space Station," AIAA Paper 87-0398, Jan. 1987. (NASA TM-88877).

5. Whalen, M.V. and Grisnik, S.P., "Compatibility of Grain-Stabilized Platinum With Candidate Propellants For Resistojets," AIAA Paper 85-2014, Sept. 1985. (NASA TM-87118).

6. Broyley, L., Serafini, J.S., Hoffman, D.J., and Zana, L.M., "Effect of Nozzle Geometry on the Resistojet Exhaust Plume," AIAA Paper 87-2121, June 1987.

7. Gruber, R.P., "Resistojet Control and Power for High-Frequency ac Buses," AIAA Paper 87-0994, May 1987. (NASA TM-89860).

8. Morren, W.E. and Sovey, J.S., "2000-Hour Cyclic Endurance Test of a Laboratory Model Multipropellant Resistojet," AIAA Paper 87-0993, May 1987. (NASA TM-89854).

9. Heckert, B.J., "Space Station Resistojet System Requirements and Interface Definition Study," RI/RD87-109, Rockwe11 Internationa1, Canoga Park, CA, Feb. 1987. (NASA CR-179581). 
10. Tacina, R.R., "Conceptual Design and Integration of a Space Station Resistojet Propulsion Assembly," AIAA Paper 87-1860, June 1987.

(NASA TM-89847).

11. Pugmire, T.K., Cann, G.L., Meckert, B.L., and Sovey, J.S., "A 10,000 Hour Life Multipropellant Engine for Space Station Applications," AIAA Paper 86-1403, June 1986 .

12. Haag, T.W. and Curran, F.M., "Arcjet Starting Reliability: A Multistart Test on Hydrogen/Nitrogen Mixtures," AIAA Paper 87-1061, May 1987. (NASA TM-89867).

13. Greco, R.W., Bliss, J.R., and Wilkinson, H.C., "Development of a Biowaste Resistojet Propulsion System Propellant Management and Control Subsystem," AIAA Paper 72-0440, Apr. 1972.

14. Penko, P.F., Manzella, D.H., Dewitt, K.J., and Keith, T.G., "Effect of Ambient Pressure on the Performance of a Resistojet," AIAA Paper 87-0991, May 1987.

15. Sovey, J.S., Penko, P.F., Grisnik, S.P., and Whalen, M.V., "Vacuum Chamber Pressure Effects on Thrust Measurements of Low-Reynolds-Number Nozzles," Journal of Propulsion and Power, Vo1. 2, No. 5, Sept.-Oct. 1986, pp. 385-389.

16. Pugmire, T.K., Shaw, R., and Enos, G.R., "Applied Resistojet Technology," Journal of Spacecraft and Rockets, Vol. 8, No. 1, Jan. 1971, pp. 63-68.

TABLE I. - ENGINEERING MODEL RESISTOJET DESIGN CHARACTERISTICS SUMMARY

- Heater-coiled, sheathed

- Center conductor

- Insulation

- Sheath

- Length

- Heat exchanger

- Material

- Flow path

- Design chamber pressure

- Thermal insulation

- Outer shroud material

- Maximum operating temperature (design)

- Weight

- Envelope
Pt-10 percent $\mathrm{Rh}, 0.156 \mathrm{~cm}$ diameter $\mathrm{Mg0}, 0.069 \mathrm{~cm}$ radial thickness Grain-stabilized Pt, $0.048 \mathrm{~cm}$ wall $3.3 \mathrm{~m}$ before colling

Grain-stabllized Pt

36 channels $0.05 / \mathrm{cm}$ wide $\times 0.127 \mathrm{~cm}$ deep $\times 10.2 \mathrm{~cm}$ long

0.1 to $0.3 \mathrm{MPa}$

10 radiation shields - five $0.003 \mathrm{~cm}$ thick Pt

- five $0.010 \mathrm{~cm}$ thick $\mathrm{Ni}$

Incone 1

$1400{ }^{\circ} \mathrm{C}$

$3.6 \mathrm{~kg}$

$24.1 \mathrm{~cm}$ long $\times 10.2 \mathrm{~cm}$ diameter 
TABLE II. - PERFORMANCE CHARACTERIZATION TEST MATRIX

[Gaseous propellants.]

\begin{tabular}{|c|c|c|c|c|c|c|c|c|}
\hline$\underset{\mathrm{A}}{\text { Current, }}$ & $\begin{array}{c}\text { Pressure, } \\
\mathrm{MPa}\end{array}$ & $\mathrm{H}_{2}$ & $\mathrm{He}$ & $\mathrm{CH}_{4}$ & Alr & $\mathrm{N}_{2}$ & Ar & $\mathrm{CO}_{2}$ \\
\hline 0 & $\begin{array}{r}0.14 \\
.27\end{array}$ & $\begin{array}{l}x \\
x\end{array}$ & $\begin{array}{l}x \\
x\end{array}$ & $\begin{array}{l}x \\
x\end{array}$ & $\begin{array}{l}x \\
x\end{array}$ & $\begin{array}{l}x \\
x\end{array}$ & $\begin{array}{l}x \\
x\end{array}$ & $\begin{array}{l}X \\
X\end{array}$ \\
\hline 18.5 & $\begin{array}{l}.14 \\
.27\end{array}$ & $\begin{array}{l}x \\
-\end{array}$ & $\begin{array}{l}x \\
x\end{array}$ & $\begin{array}{l}x \\
x\end{array}$ & $\begin{array}{l}x \\
x\end{array}$ & $\begin{array}{l}x \\
x\end{array}$ & $\begin{array}{l}x \\
x\end{array}$ & $\begin{array}{l}x \\
x\end{array}$ \\
\hline 23.0 & $\begin{array}{l}.14 \\
.27\end{array}$ & $\begin{array}{l}x \\
x\end{array}$ & $\begin{array}{l}x \\
x\end{array}$ & $\begin{array}{l}x \\
x\end{array}$ & $\begin{array}{l}x \\
x\end{array}$ & $\begin{array}{l}x \\
x\end{array}$ & $\begin{array}{l}x \\
-\end{array}$ & $\begin{array}{l}x \\
x\end{array}$ \\
\hline
\end{tabular}

TABLE A-1. - ENGINEERING MODEL RESISTOJET CHARACTERIZATION DATA

[Propellant: Hydrogen.]

\begin{tabular}{|l|r|r|r|r|r|r|}
\hline Chamber pressure, N/ $\mathrm{cm}^{2}$ & 13.8 & 13.9 & 13.9 & 13.9 & 27.6 & 27.8 \\
Mass flow rate, $\mathrm{kg} / \mathrm{hr}$ & .2113 & .1350 & .1645 & .2110 & .3586 & .4356 \\
Thrust, N & .145 & .141 & .145 & .145 & .310 & .303 \\
Specific impulse, s & 253 & 385 & 325 & 253 & 318 & 256 \\
Voltage, V & 0 & 14.3 & 9.1 & 0 & 10.9 & 0 \\
Current, A & & 23.0 & 18.5 & & 23.0 & \\
Resistance, $\Omega$ & & .622 & .492 & & .474 & \\
Power, W & & 329 & 168 & & 251 & \\
\hline
\end{tabular}

TABLE A-2. - ENGINEERING MODEL RESISTOJET CHARACTERIZATION DATA

[Propellant: Helium.]

\begin{tabular}{|l|r|r|r|r|r|r|r|}
\hline Chamber pressure, N/cm² & 27.7 & 13.7 & 13.9 & 13.7 & 27.6 & 13.9 & 27.4 \\
Mass flow rate, kg/hr & .425 & .141 & .166 & .300 & .644 & .313 & .518 \\
Thrust, N & .286 & .109 & .118 & .133 & .286 & .135 & .287 \\
Specific impulse, S & 247 & 284 & 261 & 159 & 164 & 158 & 204 \\
Voltage, V & 14.0 & 19.6 & 13.3 & 0 & 0 & 0 & 9.0 \\
Current, A & 23.0 & 23.0 & 18.5 & & & & 18.5 \\
Resistance, $\Omega$ & .609 & .852 & .719 & & & & .487 \\
Power, W & 322 & 451 & 246 & & & & 167 \\
\hline
\end{tabular}


TABLE A-3. - ENGINEERING MODEL RESISTOJET CHARACTERIZATION DATA

[Propellant: Methane.]

\begin{tabular}{|l|r|r|r|r|r|r|r|r|}
\hline Chamber pressure, N/cm² & 13.9 & 13.9 & 13.9 & 27.9 & 27.5 & 13.9 & 13.8 & 27.4 \\
Mass flow rate, kg/hr & .623 & .634 & .637 & 1.32 & .839 & .312 & .374 & .986 \\
Thrust, N & .169 & .169 & .169 & .351 & .355 & .163 & .165 & .351 \\
Specific impulse, S & 100 & 98.1 & 97.5 & 97.5 & 155 & 192 & 162 & 131 \\
Voltage, V & 0 & 0 & 0 & 0 & 14.1 & 17.9 & 11.8 & 9.5 \\
Current, A & & & & & 23.0 & 23.0 & 18.5 & 18.5 \\
Resistance, $\Omega$ & & & & & .613 & .778 & .638 & .514 \\
Power, W & & & & & 324 & 412 & 218 & 176 \\
\hline
\end{tabular}

TABLE A-4. - ENGINEERING MODEL RESISTOJET CHARACTERIZATION DATA

[Propellant: Nitrogen.]

\begin{tabular}{|l|r|r|r|r|r|r|}
\hline Chamber pressure, $\mathrm{N} / \mathrm{cm}^{2}$ & 27.6 & 13.8 & 13.8 & 27.6 & 13.8 & 27.7 \\
Mass flow rate, $\mathrm{kg} / \mathrm{hr}$ & .875 & .378 & .418 & 1.04 & .828 & 1.73 \\
Thrust, N & .332 & .149 & .153 & .338 & .162 & .336 \\
Specific impulse, S & 140 & 145 & 134 & 119 & 71.1 & 71.2 \\
Voltage, V & 18.7 & 21.5 & 15.1 & 12.1 & 0 & 0 \\
Current, A & 23.0 & 23.0 & 18.5 & 18.5 & & \\
Resistance, $\Omega$ & .813 & .935 & .816 & .654 & & \\
Power, W & 430 & 495 & 278 & 224 & & \\
\hline
\end{tabular}

TABLE A-5. - ENGINEERING MODEL RESISTOJET CHARACTERIZATION

DATA

[Propellant: Air.]

\begin{tabular}{|l|r|r|r|r|r|r|}
\hline Chamber pressure, N/cm² & 13.8 & 27.6 & 27.4 & 13.9 & 27.6 & 13.9 \\
Mass flow rate, $\mathrm{kg} / \mathrm{hr}$ & .817 & 1.69 & .300 & .358 & 1.04 & .414 \\
Thrust, N & .167 & .335 & .133 & .149 & .337 & .143 \\
Specific impulse, S & 72.6 & 72.8 & 159 & 153 & 119 & 136 \\
Voltage, V & 0 & 0 & 0 & 21.8 & 11.8 & 14.7 \\
Current, A & & & & 23.0 & 18.5 & 18.5 \\
Resistance, $\Omega$ & & & & .948 & .638 & .795 \\
Power, W & & & & 501 & 218 & 272 \\
\hline
\end{tabular}


TABLE A-6. - ENGINEERING MODEL RESISTOJET CHARACTERIZATION DATA

[Propellant: Argon.]

\begin{tabular}{|l|r|r|r|r|r|r|r|}
\hline Chamber pressure, N/cm² & 13.8 & 27.5 & 27.6 & 27.6 & 13.9 & 13.8 & 14.1 \\
Mass flow rate, kg/hr & 1.03 & 2.12 & .958 & 1.08 & .500 & 1.03 & .472 \\
Thrust, N & .149 & .314 & .305 & .309 & .143 & .149 & .150 \\
Specific impulse, S & 53.6 & 54.5 & 117 & 105 & 105 & 536 & 117 \\
Voltage, V & 0 & 0 & 21.3 & 14.6 & 15.9 & 0 & 22.0 \\
Current, A & & & 23.0 & 18.5 & 18.5 & & 23.0 \\
Resistance, $\Omega$ & & & .926 & .789 & .860 & & .957 \\
Power, W & & & 490 & 270 & 294 & & 506 \\
\hline
\end{tabular}

TABLE A-7. - ENGINEERING MODEL RESISTOJET CHARACTERIZATION DATA

[Propellant: Carbon Dioxide.]

\begin{tabular}{|l|r|r|r|r|r|r|r|r|}
\hline Chamber pressure, N/cm² & 27.9 & 27.7 & 15.0 & 27.6 & 20.8 & 13.9 & 13.9 & 27.6 \\
Mass flow rate, kg/hr & 2.13 & 2.11 & 1.11 & 1.06 & .72 & .443 & .536 & 1.37 \\
Thrust, N & .374 & .371 & .193 & .344 & .252 & .158 & .161 & .346 \\
Specific impulse, S & 64.5 & 64.5 & 63.8 & 119 & 128 & 131 & 110 & 92.5 \\
Voltage, V & 0 & 0 & 0 & 17.6 & 19.3 & 21.2 & 13.6 & 11.2 \\
Current, A & & & & 23.0 & 23.0 & 23.0 & 18.5 & 18.5 \\
Resistance, $\Omega$ & & & & .765 & .839 & .922 & .735 & .605 \\
Power, W & & & & 405 & 444 & 488 & 252 & 207 \\
\hline
\end{tabular}

TABLE A-8. - RESISTOJET PERFORMANCE WITH STEAM PROPELLANT

[Typical chamber pressure: $21 \mathrm{~N} / \mathrm{cm}^{2}$.]

\begin{tabular}{|l|r|r|r|r|r|r|r|}
\hline Thruster power, W & 73 & 181 & 280 & 431 & 426 & 602 & 692 \\
Steam generated power, $W$ & 708 & 621 & 627 & 490 & 480 & 470 & 466 \\
Total power, W & 781 & 802 & 907 & 921 & 906 & 1072 & 1158 \\
Mass flow rate, kg/hr & .77 & .64 & .60 & .53 & .53 & .49 & .45 \\
Thrust, N & 240 & 220 & 240 & 222 & 230 & 230 & 230 \\
Specific impulse, s & 115 & 127 & 144 & 157 & 162 & 172 & 184 \\
\hline
\end{tabular}

TABLE A-9. - RESISTOJET PERFORMANCE WITH LIQUID WATER PROPELLANT

\begin{tabular}{|l|r|r|r|r|}
\hline Power, W & 198 & 289 & 395 & 505 \\
Mass flow rate, $\mathrm{kg} / \mathrm{hr}$ & .22 & .19 & .32 & .32 \\
Thrust, N & 78.6 & 84.2 & 102 & 122 \\
Specific impulse, S & 134 & 159 & 117 & 137 \\
Chamber pressure, N/cm² & 7 & 8 & 10 & 11 \\
\hline
\end{tabular}




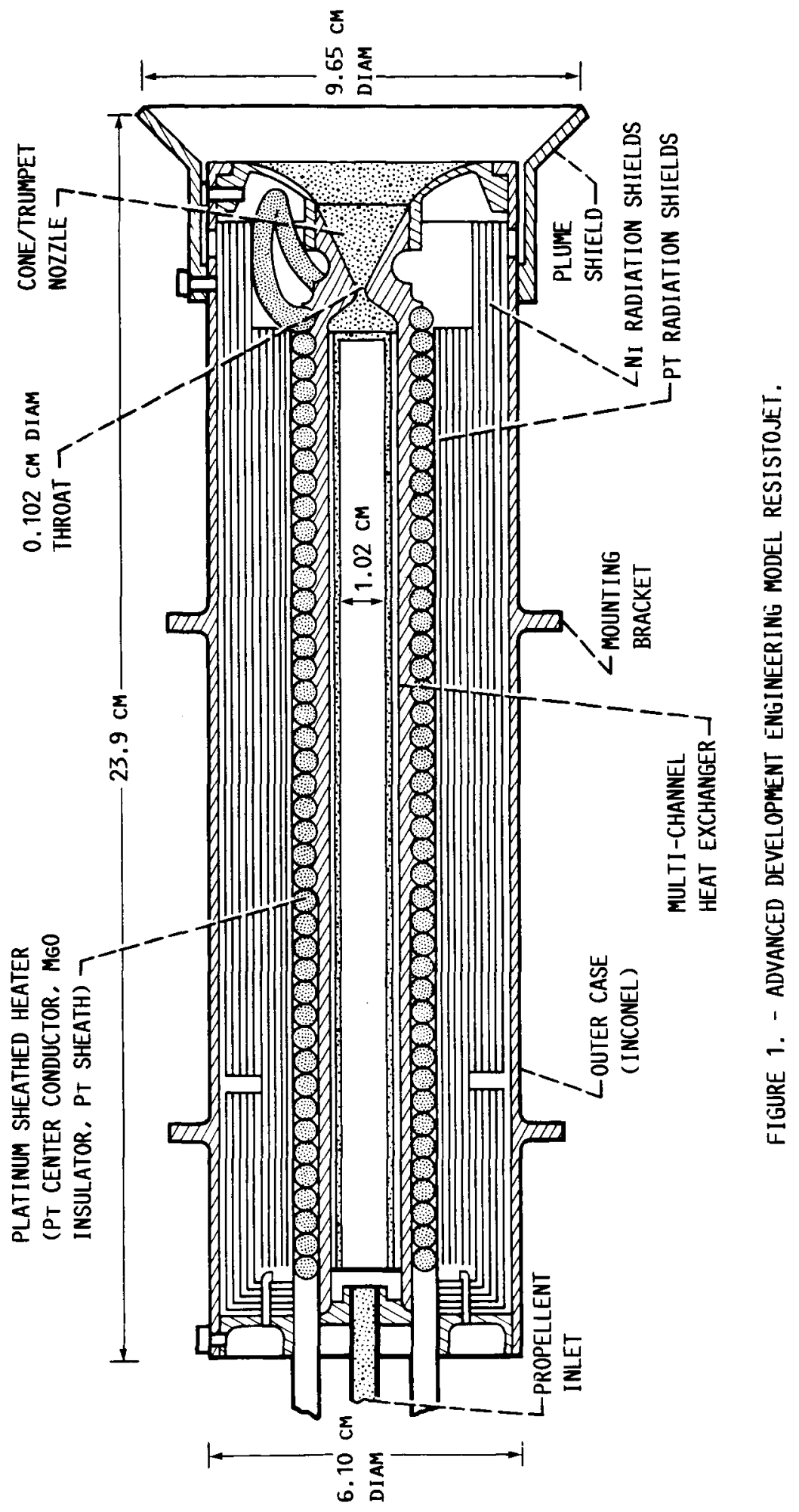




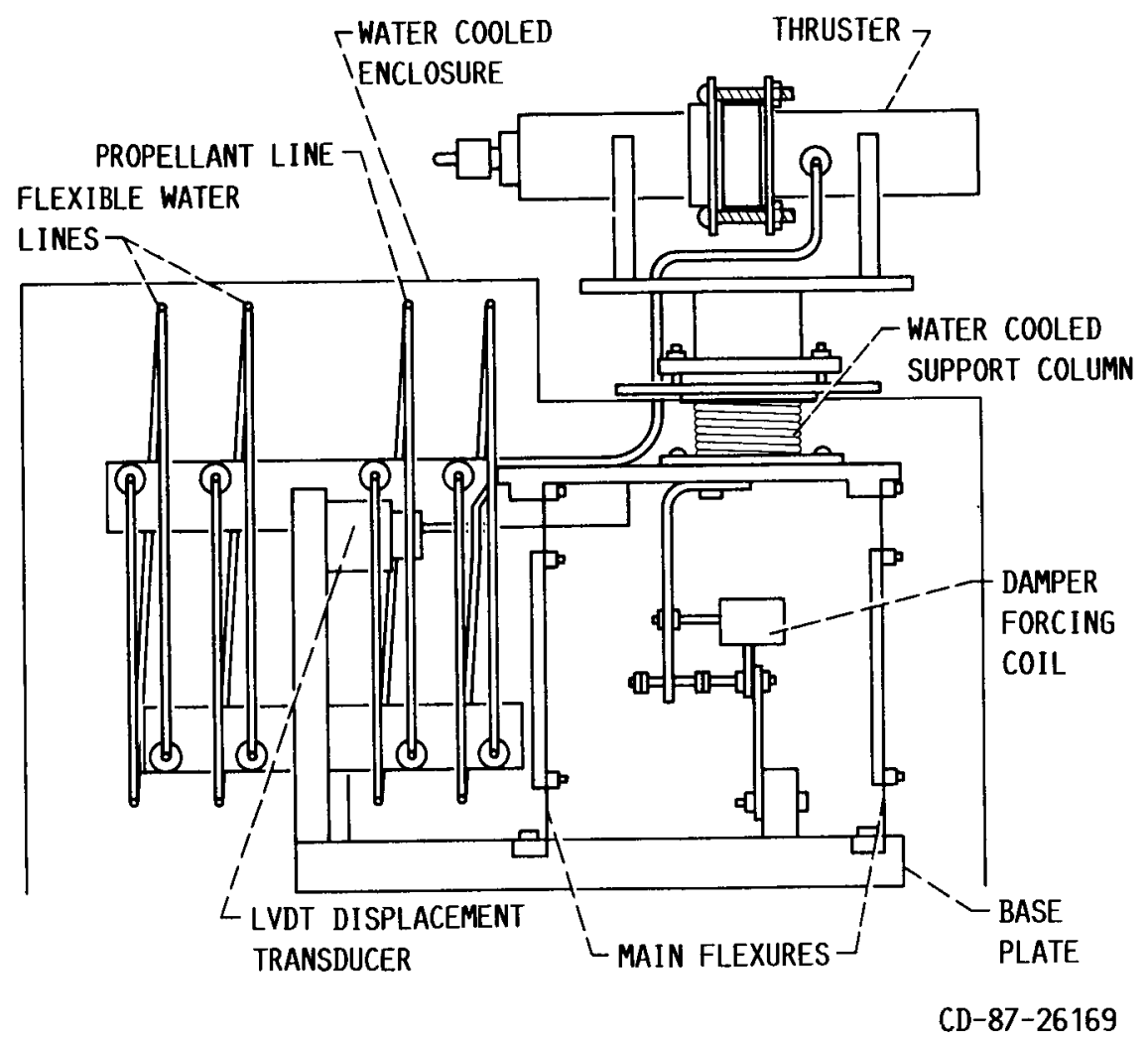

FIGURE 2. - SCHEMATIC DIAGRAM OF THRUST STAND WITH THRUSTER MOUNTED. 


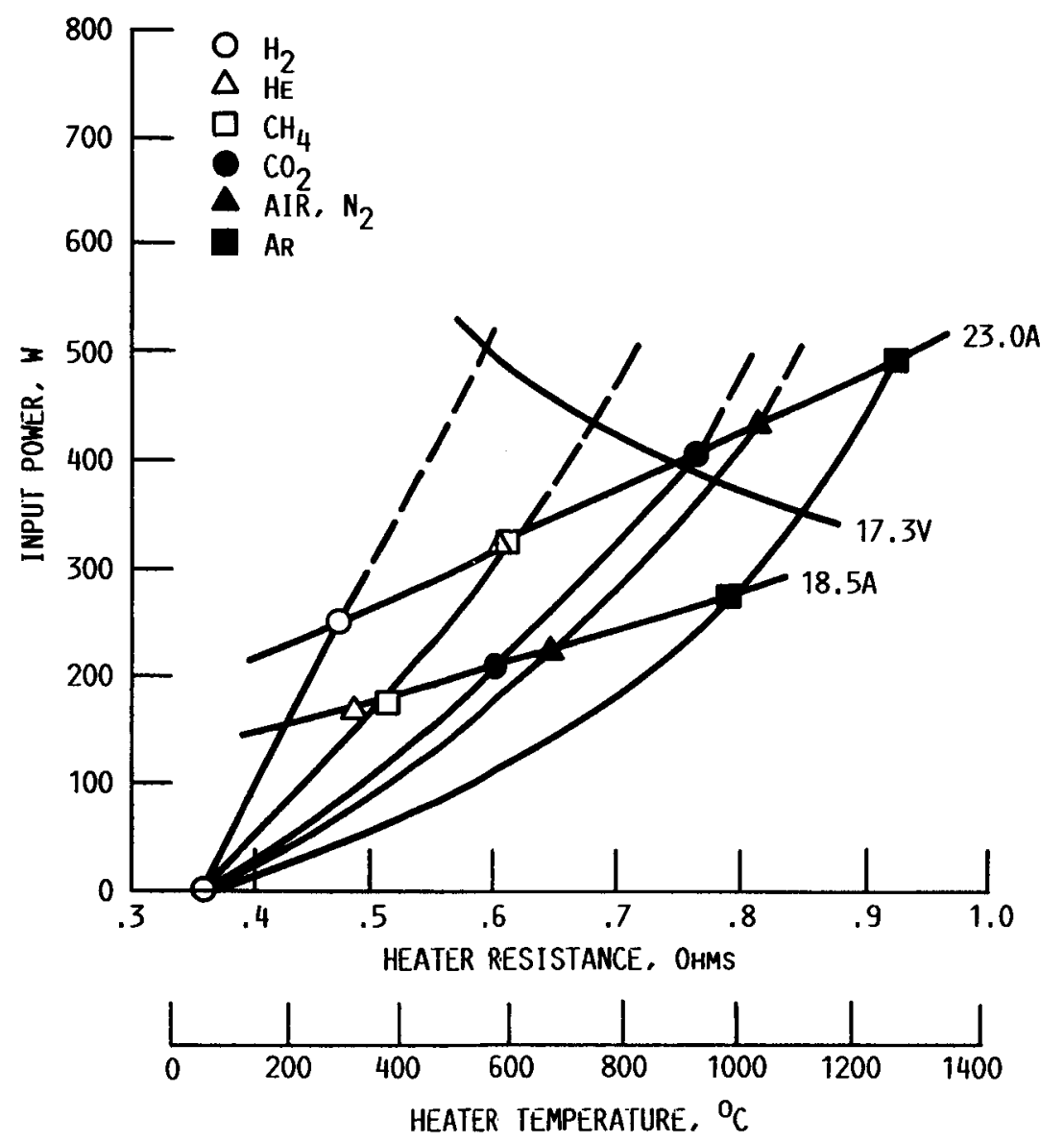

FIGURE 3. - ELECTRICAL CHARACTERISTICS OF ENGINEERING MODEL RESISTOJET AT CONSTANT PROPELLANT INLET PRESSURE (0.14 MPA). 


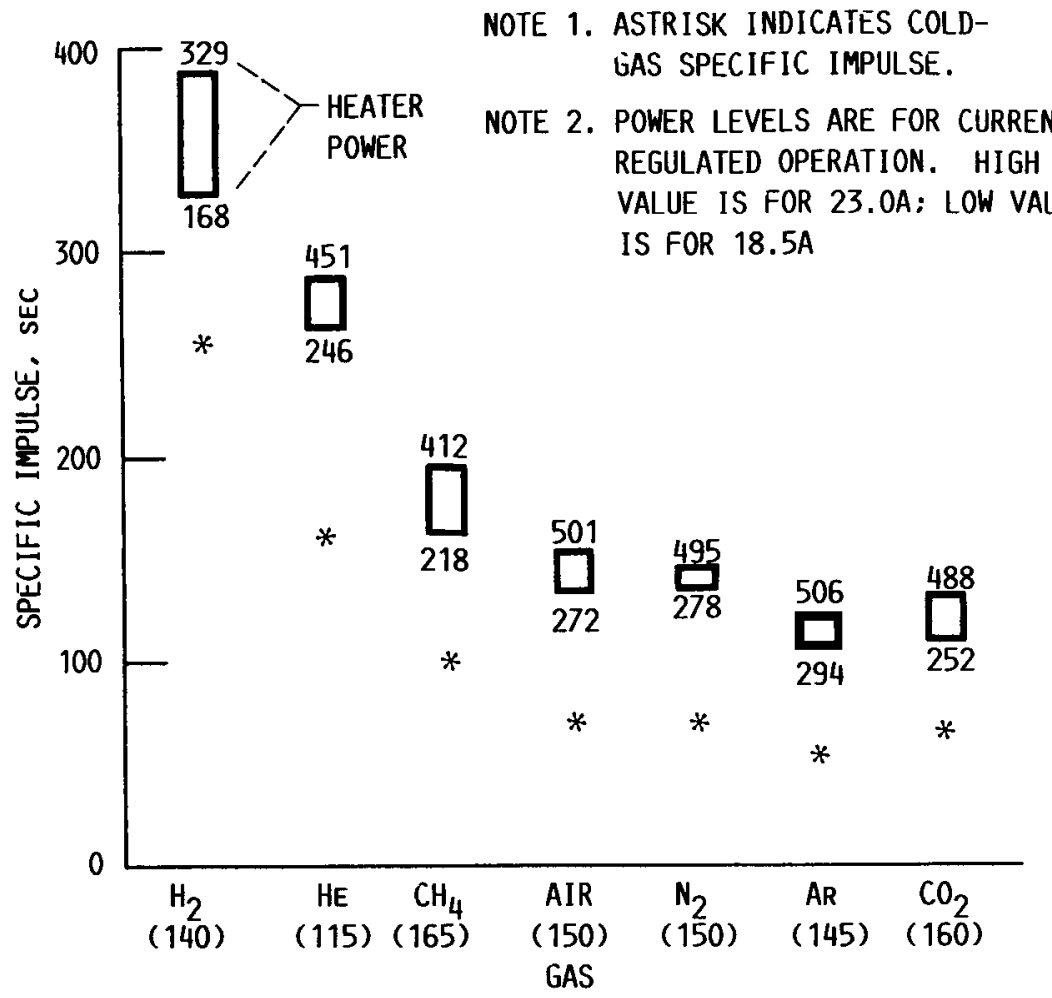

(NOMINAL THRUST, MN)

FIGURE 4. - SPECIFIC IMPULSE AND POWER RANGES FOR ENGINEERING MODEL RESISTOJET FOR INLET PRESSURE OF 0.14 MPA.

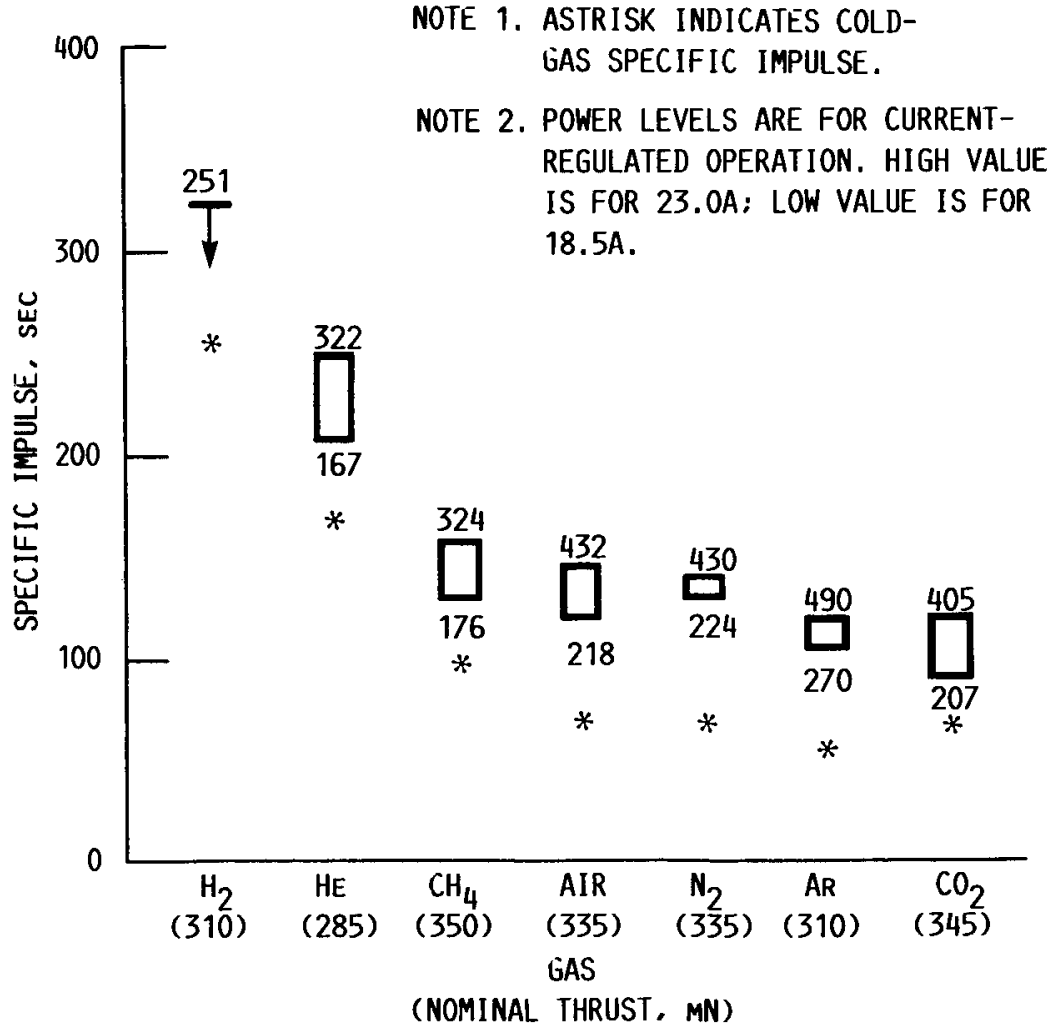

FIGURE 5. - SPECIFIC IMPULSE AND POWER RANGES FOR ENGINEERING MODEL RESISTOJET FOR INLET PRESSURE OF 0.27 MPA. 


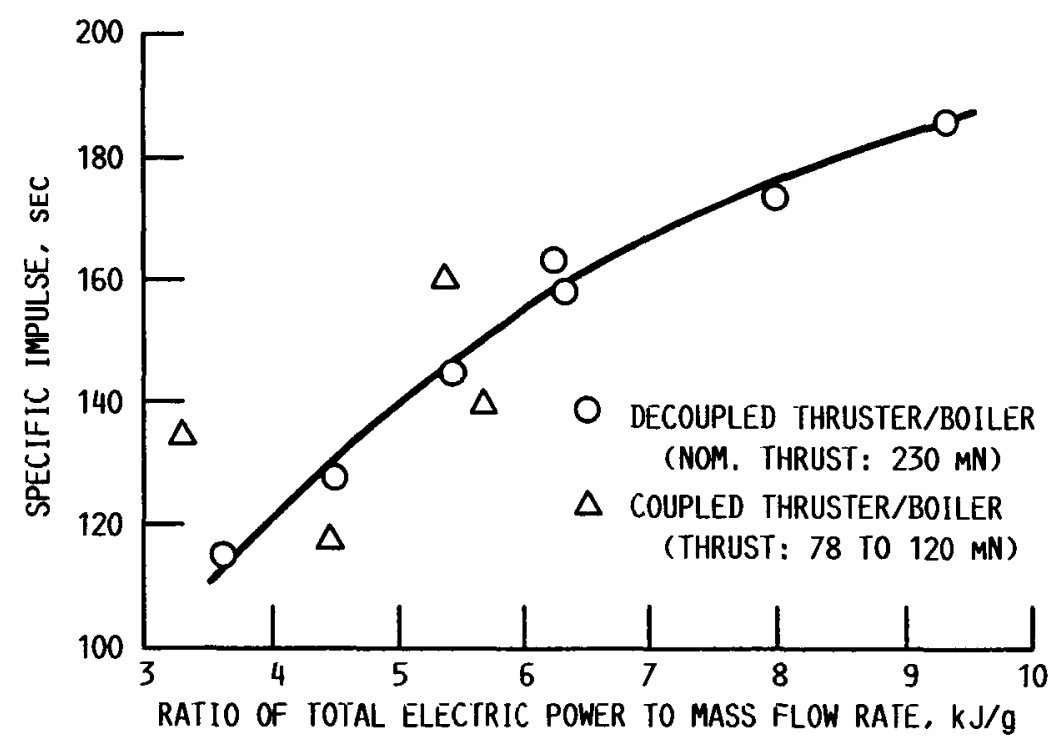

FIGURE 6. - COMPARISON OF COUPLED AND DECOUPLED RESISTOJET OPERATION USING WATER PROPELLANT. 
ORGMUA PAGE IS

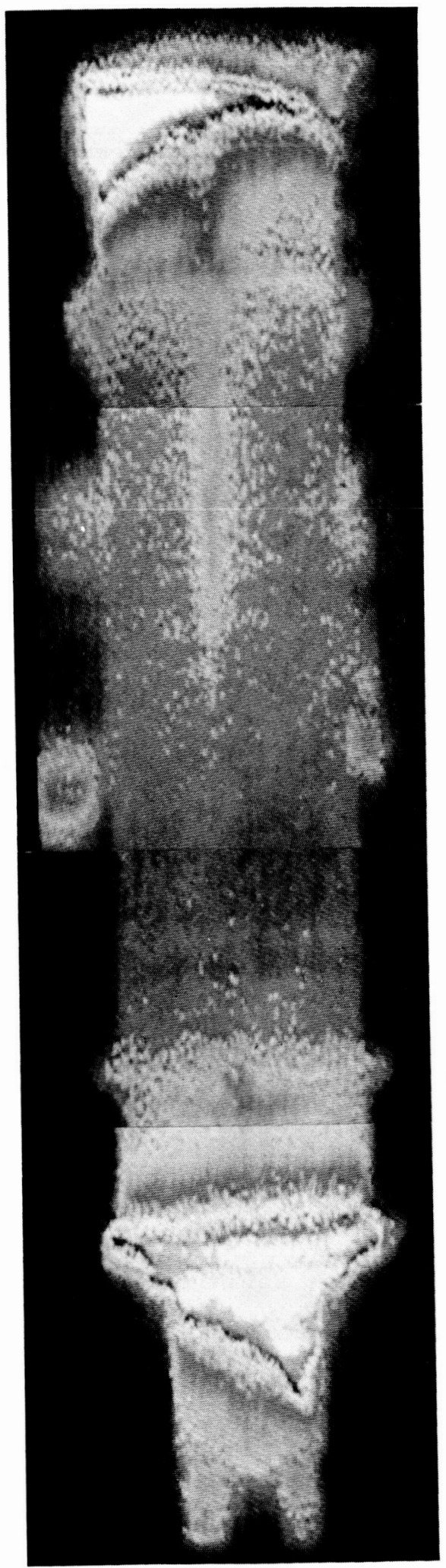

OF POOR QUALTY

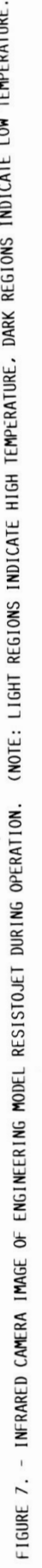


ORIGINAL PAOE IS

OF POOR OUMLTY

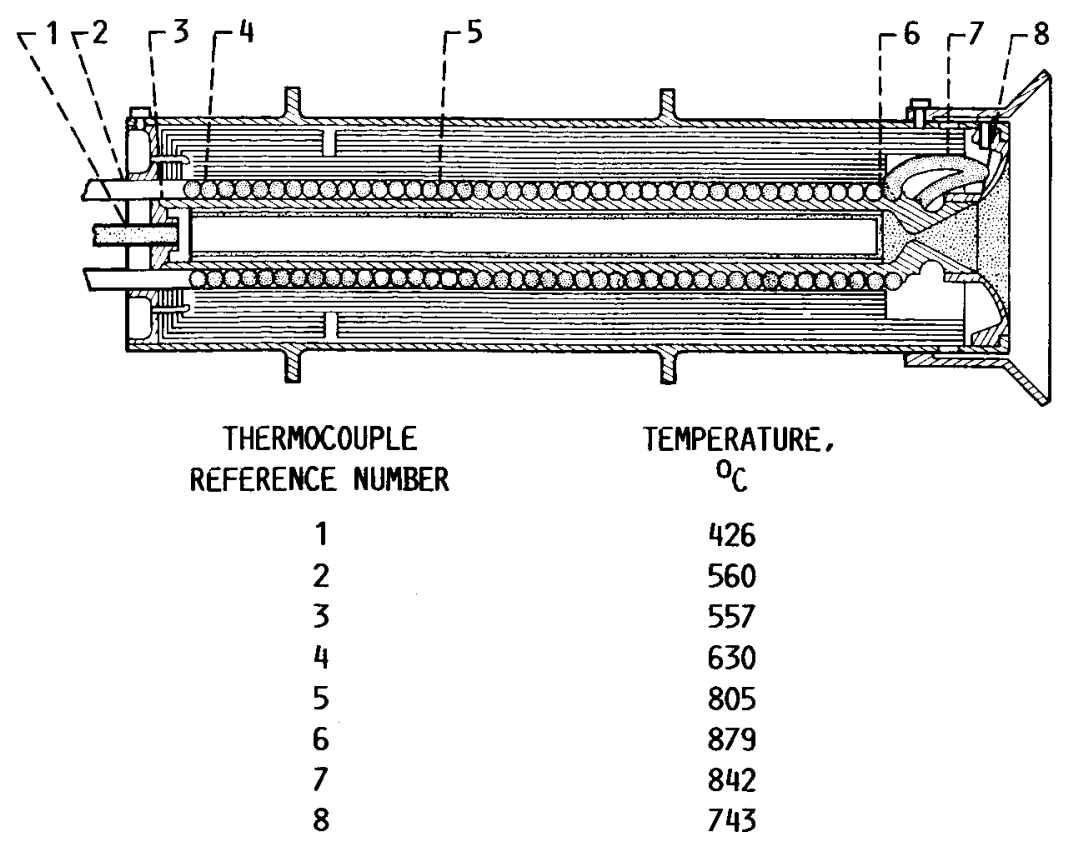

FIGURE 8. - ENGINEERING MODEL THRUSTER TEMPERATURE PROFILE FOR OPERATION ON $\mathrm{CO}_{2}$ AT 335 MN THRUST, 120 SECONDS SPECIFIC IMPULSE (0.27 MPA INLET PRESSURE, 23.0 A HEATER CURRENT).

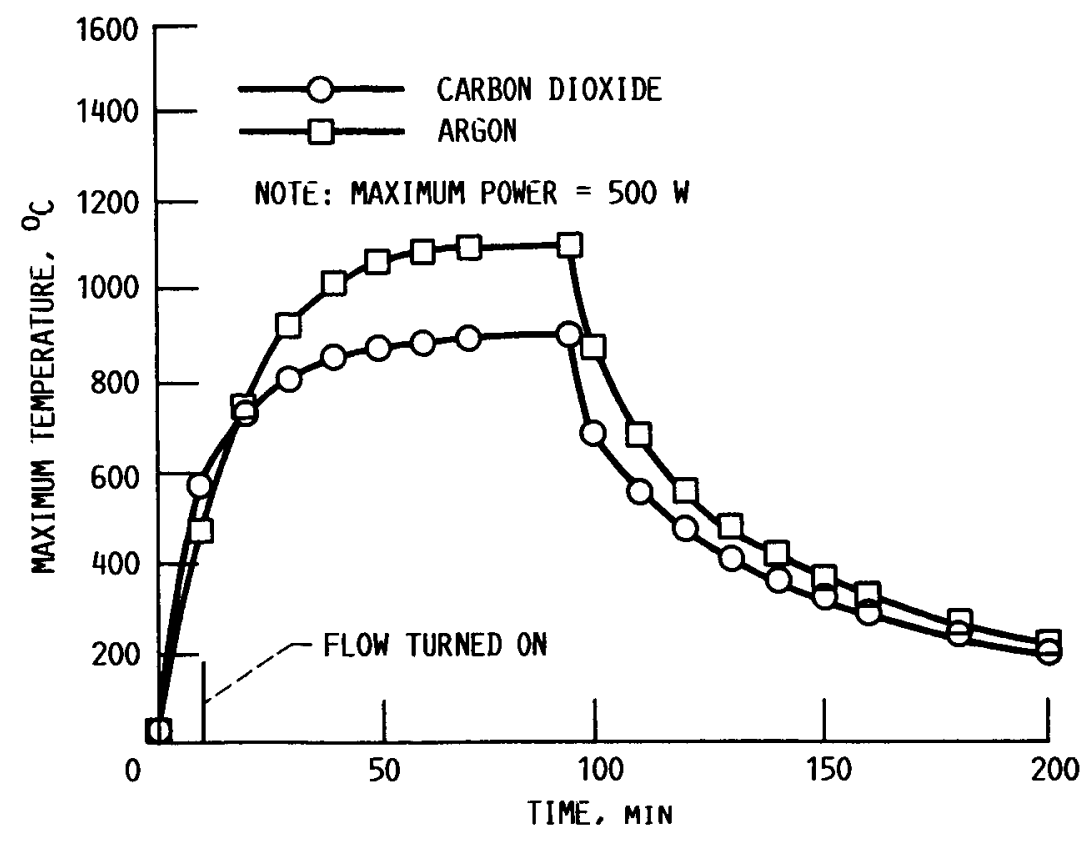

FIGURE 9. - THERMAL TRANSIENT RESPONSE OF ENGINEERING MODEL RESISTOJET ON CO2 AND AR PROPELLANTS. 


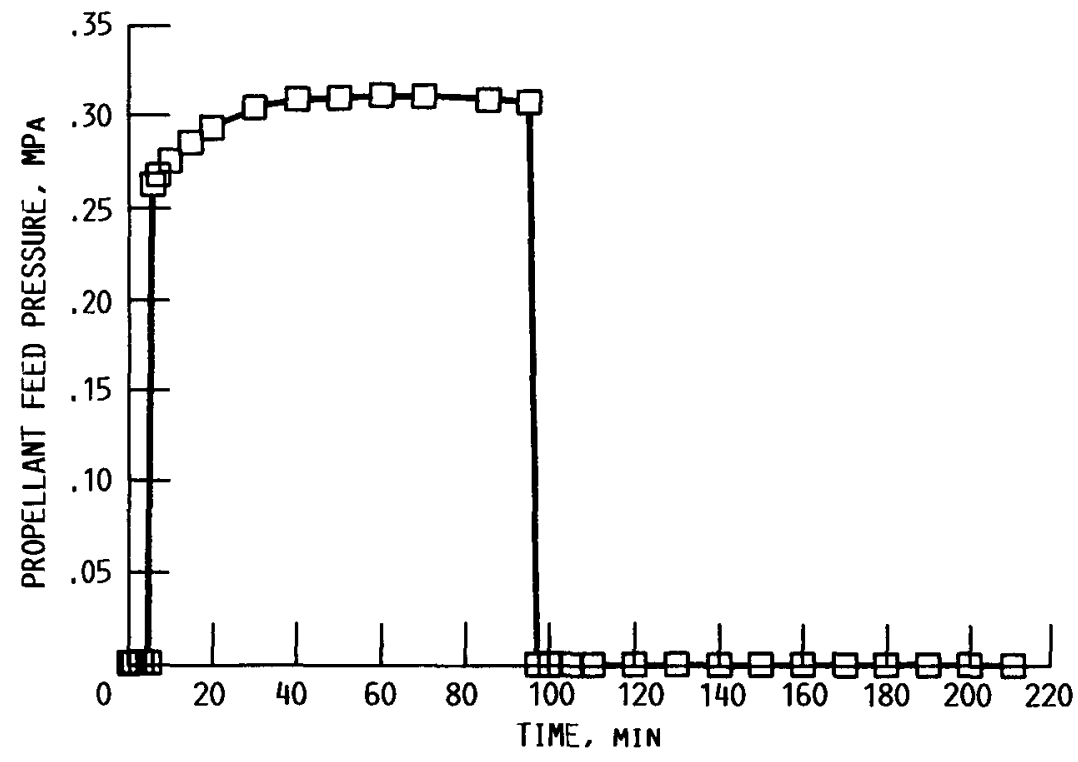

FIGURE 10. - VARIATION OF FEED PRESSURE WITH TIME FOR ENGINEERING MODEL RESISTOJET OPERATING ON $\mathrm{CO}_{2}, 23.0$ A HEATER CURRENT. 


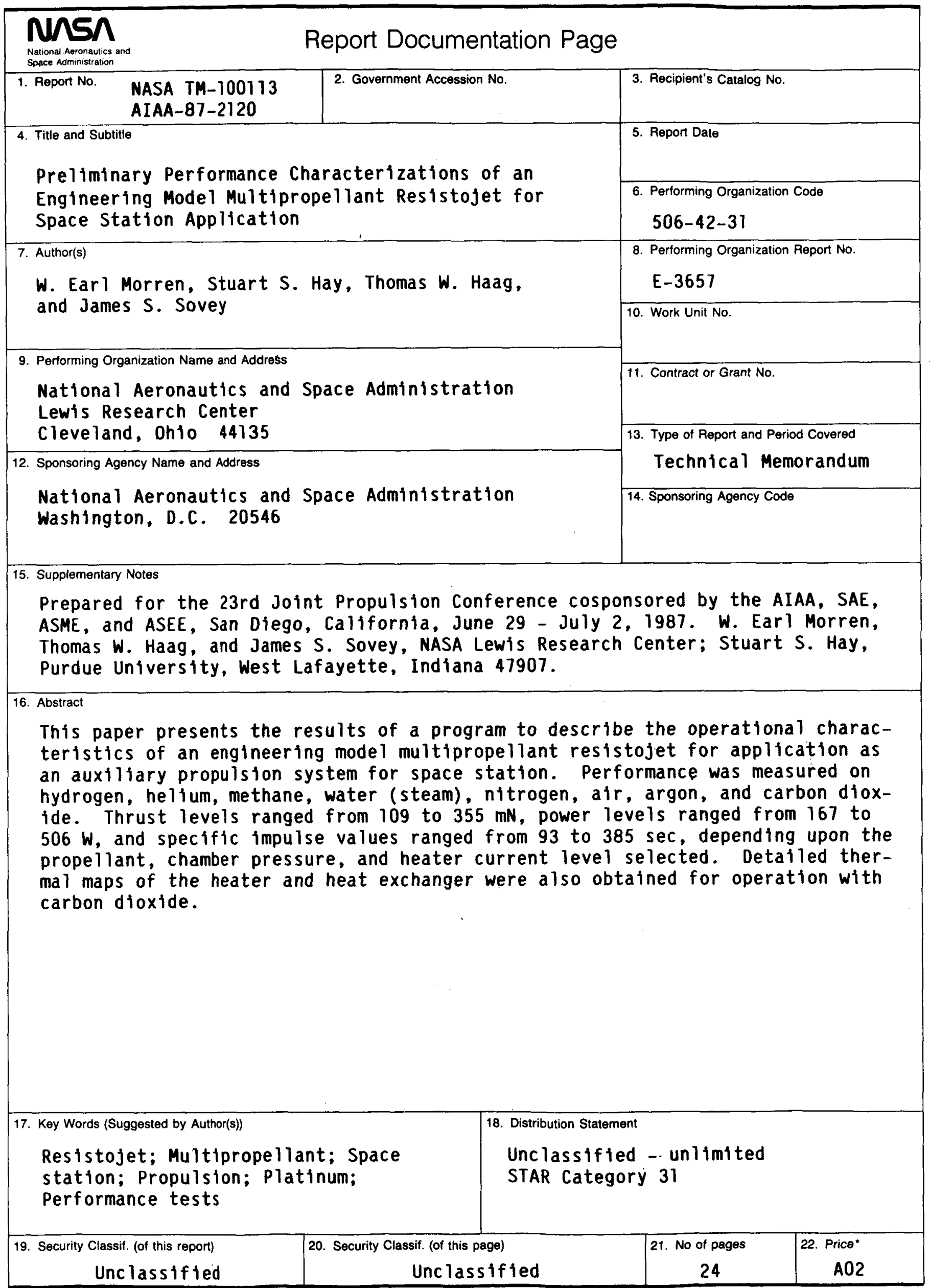

